\title{
Research and application of water jet technology in well completion and stimulation in China
}

\author{
Li Gensheng*, Huang Zhongwei, Tian Shouceng and Shen Zhonghou \\ State Key Laboratory of Petroleum Resource and Prospecting, China University of Petroleum, Beijing 102249, China \\ (C) China University of Petroleum (Beijing) and Springer-Verlag Berlin Heidelberg 2010
}

\begin{abstract}
In recent years, rapid progress in the use of high pressure water jets (HPWJ) has been made in oil and gas well drilling, completion, and stimulation; and good results have been achieved in field applications. Advances in technologies and developments of well completion and stimulation with hydrajet are reviewed in this paper. Experiments were conducted to study the characteristics of abrasive water jetting and to optimize jet parameters, which can provide methods for the well completion and hydrajet fracturing. Deep-penetrating hydrajet perforating can create a 2-3 m clean hole with a diameter of 20-35 mm. Multilayer hydrajet fracturing is a process whereby multiple layers are stimulated in a single run without using mechanical packers, thereby reducing operation procedure and risk. Multilateral radial wells can be drilled using hydraulic jetting up to $100 \mathrm{~m}$ in length. The technique to remove sand particles and plugs with rotating self-resonating cavitating water jets in horizontal wellbores has been developed and oilfield-tested, which shows promising, cost effective prospects.
\end{abstract}

Key words: Water jet, abrasive jet, well completion, perforation, stimulation, horizontal drilling with hydrajet

\section{Introduction}

The high pressure water jet (HPWJ) technique has been widely used for many years around the world in different fields, such as mining, cutting, cleaning, and scarifying materials (Maurer, 1980; Summers, 1994; Vijay, 1995; Kobayashi, 2007). In the last 30 years, rapid progress in the utilization of high-pressure water jet has been made in oil and gas well drilling, completion, and stimulation; and good results have been achieved in field applications (Shen, 1997; $\mathrm{Li}$ et al, 2005). Well completion and stimulation techniques using water jet technique provide alternative approaches and have significant impact on enhanced oil recovery and reduction in costs. This paper considers water jet techniques and their applications in well completion and stimulation in China, including abrasive jet perforating, deep-penetrating hydrajet perforating, multilayer hydrajet fracturing, and radial horizontal drilling with hydrajet.

\section{Abrasive jet perforating}

Shaped charge jet perforating is commonly used in conventional oil and gas wells, but this method creates a lowpermeability crushed-zone surrounding the wellbore. The permeability of the damaged zone decreases to $10 \%-35 \%$ of the original, and its thickness is $6-12.5 \mathrm{~mm}$, even reaching

*Corresponding author. email: ligs@cup.edu.cn

Received January 16, 2009
$25 \mathrm{~mm}$. The procedure of abrasive jet perforating is as follows: The slurry containing abrasive solids is pressurized in a fracturing truck. The high-pressure slurry is pumped downhole with a tubing pump. The resulting high velocity fluid stream is ejected from the nozzles of downhole tools at a high speed to perforate the casing and near wellbore formation, and finally a perforation tunnel is created (as shown in Fig. 1). Therefore, this method can increase the near-wellbore permeability, enhance well productivity, and avoid permeability reduction caused by crushed zones (Cobbett, 1999).

Since 2004, a great number of tests have been done in laboratory to investigate the effects of various parameters on the perforation depth ( $\mathrm{Li}$ et al, 2004). The tested parameters are jetting pressure, flow rate, confining pressure, jetting time, abrasive type, abrasive concentration, abrasive size, and rock strength.

Test results demonstrated that the perforation depth and diameter increased significantly with jetting pressure. Perforation depth increased when the flow rate increased, so a long perforation tunnel might be achieved by means of high pressure and high flow rate. The confining pressure increased with well depth; the perforation depth under a specific confining pressure was much lower than that under no confining pressure. At a specified pressure, the perforation depth increased sharply with jetting time at the initial stage of abrasive jet perforating. After a period of time, the perforation depth extended to the maximum value, then the perforation depth almost did not increase any more but the tunnel 


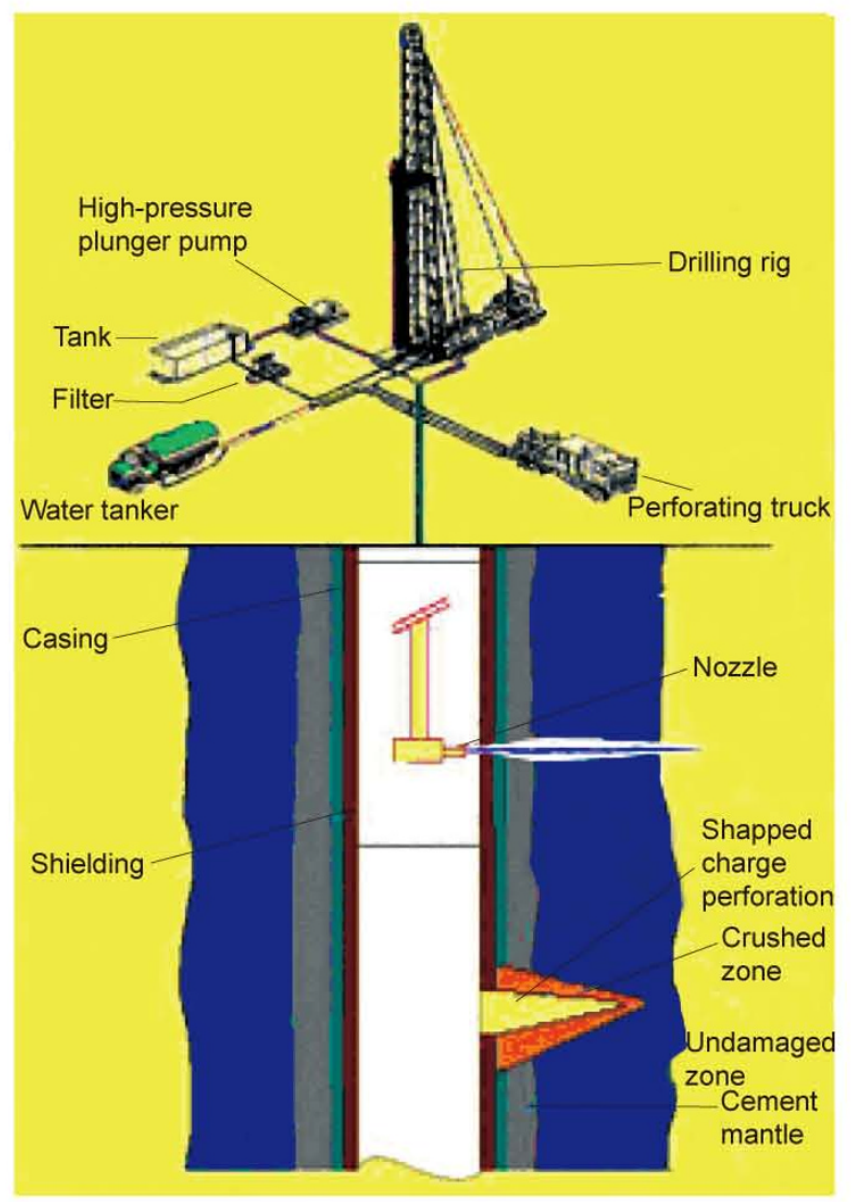

Fig. 1 Abrasive jet perforating

diameter continued to increase. In practical applications, it was better to control the abrasive jet perforating time between 15 to 30 minutes.

Different abrasive materials have different perforation effects. In general, angular abrasive materials have greater cutting ability than those rounded abrasives. At a specific pressure and flow rate, there seemed to be an optimum concentration range of abrasive materials for the perforation depth. The optimum concentration increased with pressure, and the optimum concentration range was $6 \%-8 \%$. At a specific flow rate and pressure, the jet velocity containing a high concentration of abrasive materials was lower than that containing a low concentration of abrasive materials, and the optimum abrasive grain size was 0.4-0.6 mm. Lithologic characteristics of formations had a large impact on abrasive jet perforating capability. At limestone reservoirs, abrasive jet perforating requires higher pressure and flow rate than in sandstone reservoirs. Parameters could be optimized experimentally, and these experimental results provided fundamental information for well completion and fracturing.

Based on parameters optimized in the laboratory, the abrasive jet perforating technique has already been used in oilfields in more than 10 wells. The maximum well depth extended to $4,800 \mathrm{~m}$ and the maximum perforation number was 90 . Expected results have been achieved, providing advantages for follow-up treatments. This technique can remove formation damage in the near-wellbore $0.8 \mathrm{~m}$, especially for the stripped wells mainly caused by formation blocking.

\section{Deep-penetrating hydrajet perforating}

Since 1993, deep-penetrating hydrajet perforating technique has been developed and utilized in oil reservoirs (Peters and Henson, 1993). The mechanism of this technique is illustrated in Fig. 2. Firstly, the hydraulic device is run in the hole to perforate the casing in the expected interval, afterwards a water jet tubing with nozzles at the outlet end is extended by hydraulic system and high-speed water jets are jetted from nozzles to cut the rock, meanwhile the nozzles are steadily maintained about $10 \mathrm{~cm}$ away from the exposed surface of perforated rock until the perforation depth reaches 2-3 m.

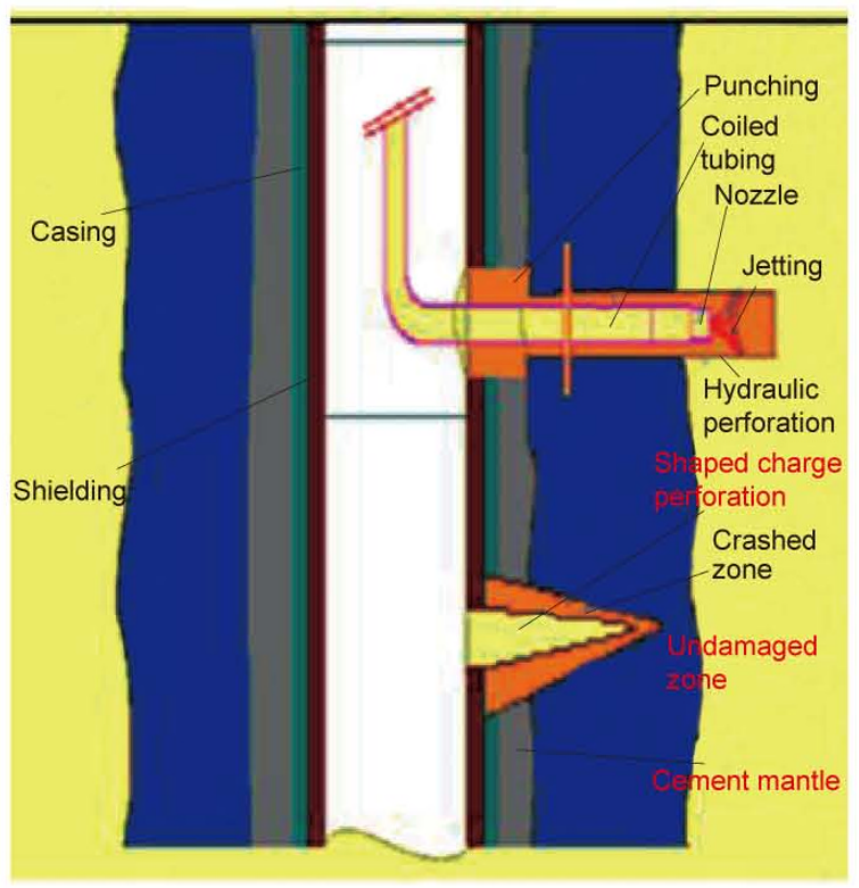

Fig. 2 Hydrajet perforating

Deep-penetrating hydrajet perforating has some advantages compared with shaped charge jet perforating: 1) To obtain a deep perforation tunnel of a great diameter. This technique belongs to ultrashort-radius horizontal perforating technology which can create a 2-3-m hole with a diameter of $20-35 \mathrm{~mm}$. The operation can enlarge drainage area and increase oil flow rate. 2) To remove the drilling damage in the immediate vicinity of the wellbore. In general, the radius of the area around the wellbore harmed by drilling process is more than $0.5 \mathrm{~m}$, sometimes reaching $2 \mathrm{~m}$. The penetration depth of a deep-penetrating jet is $2-3 \mathrm{~m}$, so the damaged zone around the wellbore can be bypassed by perforation tunnels to create connecting conduits from the wellbore to the undamaged reservoir formation. However, the maximum penetration depth of perforating charges is $0.5-0.8 \mathrm{~m}$, with an average depth of $0.4 \mathrm{~m}$, so the near-wellbore damage can 
not be removed by perforation tunnels created by a shaped charge. 3) Minor or superficial damage to the casing. Several tens or hundreds of bullets are shot one time from a charge gun, this will greatly damage the casing and speed up casing corrosion. However, hydrajet perforating hardly causes casing damage due to a lower number of perforation tunnels than the conventional method, therefore the life of oil casings is relatively longer ( $\mathrm{Li}$ et al, 2007).

To date, there are two operation methods in China, downhole control mode and surface control mode, to perforate tunnels in the desired formations, depending on the application and wellbore conditions. Deep-penetrating perforating technique using hydraulic jet (or hydrajet), which can be controlled downhole, has been applied to more than 10 wells in recent years ( $\mathrm{He}$ and $\mathrm{Hu}, 2006)$. Fig. 3 showed that the fluid production increased significantly after the perforating was carried out with downhole automatic control mode in Wei 5-19 well, Jiangsu Oilfield.

The hydrajet perforating technique, which can be controlled on the surface, was developed by China University of Petroleum and was applied to Sha11-5 well and Sha1942 well, Jiangsu Oilfield. Fig. 4 showed that the total fluid production of Sha19-42 well increased significantly.

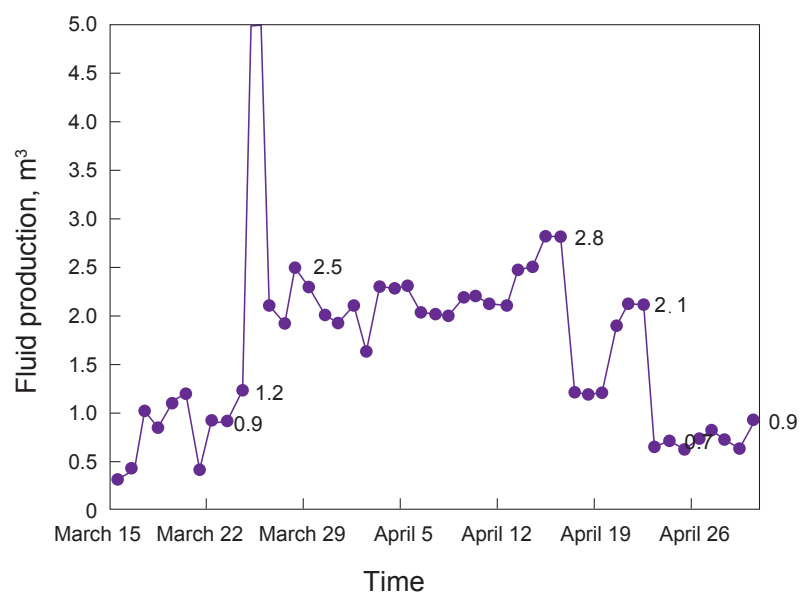

Fig. 3 A comparison of fluid production before and after hydrajet perforating in Wei 5-19 well

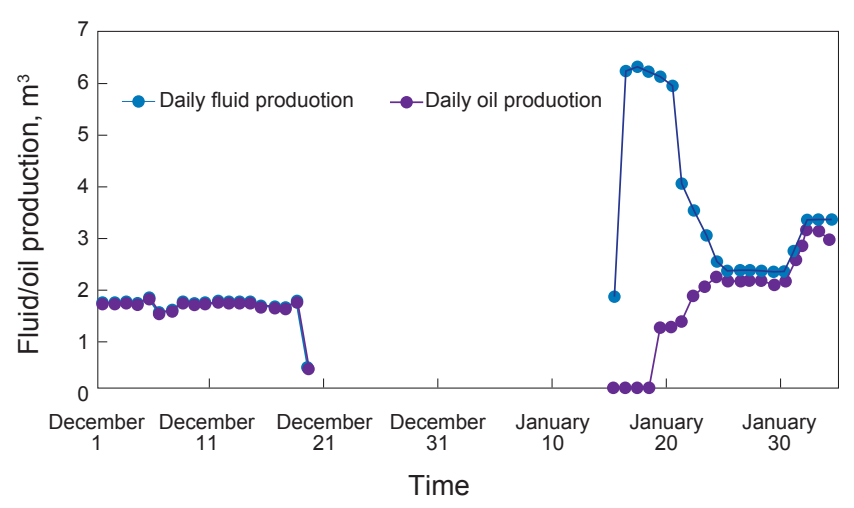

Fig. 4 A comparison of fluid/oil production before and after hydrajet perforating in Sha 19-42 well

\section{Multilayer hydrajet fracturing}

To date, staged fracturing in horizontal wells and multilayer fracturing in vertical wells are preferred stimulation treatments to increase oil production. The techniques commonly-used in multilayer fracturing or staged fracturing includes limited entry fracturing, temporary plugging agent multilayer fracturing, and mechanical packer separate layers fracturing. Limited entry fracturing requires low perforation density, which would hamper enlarging the effective radius of wellbore by perforating. During limited entry treatment a sharp pressure drop might appear at perforation tunnels and the fracture entrance, which affects the distribution of solid-carrying fluid in layers. The flow area of fractures induced by limited entry treatment is small, so proppant might easily be reversed out in the flowback and production periods. When fracturing treatment is performed in a horizontal open hole, the easiest isolation method is to use temporary plugging agents, such as halite, benzoic flake, or camphor balls. However, it is hard to control the distance between fracture initiation points along the wellhole; and it is difficult to control the proppant filling in fractures nearwellbore in the temporary plugging stage. In the cased wells, multilayer fracturing or staged fracturing treatment can be conducted by setting packers in the designed locations, but, the packers can easily stick in place after fracturing treatment, resulting in downhole problems.

In multilayer fracturing treatment using hydrajet multiple layers are stimulated in a well with one run and no mechanical packer is used, thereby reducing fracturing cost and operation risk and improving fracturing effect. A new stimulation treatment is now available that combines hydrajetting and fracturing techniques (Surjaatmadja et al, 1998; 2004). Firstly, a high-pressure water jet (HPWJ) is ejected in the desired direction to perforate formation rocks, and the high velocity fluid creates many micro-fractures at the tip of the perforation tunnel, and thus reducing the fracture initiation pressure. Hydrajet continues to flow into the perforation tunnels and then develops boosting. After closing the annulus, once the combination of jetting boosting and annular pressure exceeds rock fracture pressure, the formation rock at the tip of the perforation tunnel will be fractured (as shown in Fig. 5). When the fracture has been initiated and fracturing fluids are pumped into the annulus, the fluids are drawn by the high-velocity jetting from the annulus into the perforation tunnel and fracture; the fracture can be extended substantially. By using this technique, staged fracturing treatment can be performed several times at the designed well interval without using mechanical packers. The technique enables accurate placement of reservoir treatments down the annulus and enhances the productivity of stimulated wells and the operation safety once it is used in conjunction with an acidizing technique.

Since 2006, Changqing Oilfield and the Halliburton Company have cooperated in hydrajet fracturing in more than 10 wells. In the year of 2007, China University of Petroleum (Beijing) and Oil Recovery Engineering Research Institute of PetroChina Southwest Oil \& Gasfield Company 


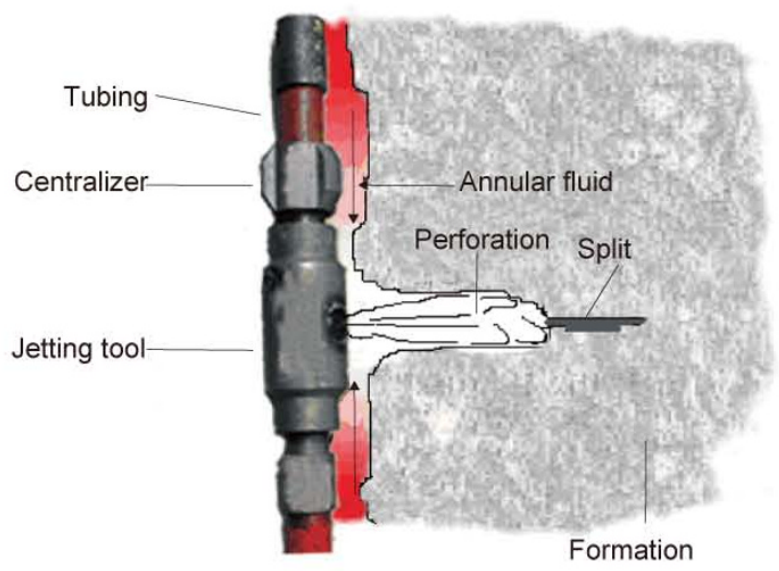

Fig. 5 Mechanism of multilayer hydrajet fracturing

worked together and used their own design and operation of multilayer hydrajet fracturing technique in field. Layer by layer hydrajet fracturing using 2-inch coiled tubing was first applied in the Baiqian 110 well. This well achieved sand fracturing in three layers in one day, layer depth was $1,105-$ $749 \mathrm{~m}, 30.32 \mathrm{~m}^{3}$ ceramsite of 20-40 mesh was used in the three layers and each layer fracturing time was 2-3 hours, the scope of work was nearly $315 \mathrm{~m}$. After treatment, the Baiqian 110 well was revived with a stable treatment gas production above $10,000 \mathrm{~m}^{3}$ per day. The Guangan $02-\mathrm{H} 9$ well, with a vertical depth of $1,700 \mathrm{~m}$ and horizontal section of $500 \mathrm{~m}$, applied hydrajet fracturing using $2 \frac{7}{8}$ inch tubing in two sections, about $50 \mathrm{~m}^{3}$ fracturing sand was used, as a result the production increased significantly from 8,000 to $70,000 \mathrm{~m}^{3} / \mathrm{d}$. Subsequently, the immovable pipe string perforation fracturing technique as tested in the Guangan 02X68 well, which $\operatorname{ran} 2 \frac{7}{8}$ inch tubing using sliding-sleeve jet fracturing tools and jetted two sections, $50 \mathrm{~m}^{3}$ fracturing sand was used in each layer and fracturing time was 2-3 $\mathrm{h}$ per layer. The Niudongping Well-2 in Toha Oilfield applied the dragging pipe string hydrajet fracturing technique in the section of 2,103-2,105 $\mathrm{m}$ and 1,989.6-1,991.6 m, about 18 $\mathrm{m}^{3}$ of fracturing sand was used for each layer and fracturing time was 2-3 h per layer, and after fracturing the production increased about 6 times, from 2.0 to $13.5 \mathrm{~m}^{3} / \mathrm{d}$.

\section{Horizontal drilling with hydrajet}

Radial drilling technique has many advantages: These include to extend the length of borehole in reservoirs, enlarge drainage area, enhance oil recovery, improve inflow profile, reduce fingering velocity, increase vertical oil recovery, explore marginal reservoirs and heavy crude oil reservoirs, reuse the top borehole, and reduce drilling cost. There are several techniques for radial wells: milling window in casing, pre-milling window in casing, open borehole sidetracking, multilateral well, bulged tube located sidetracking, and intelligent multilateral well.

Since the 1980s, Petrolphysics Ltd and China University of Petroleum have started to study ultrashort-radius lateral well with hydrajet technique (Shen, 1997; Dickinson, 1989). This technique is very significant for both onshore and offshore oilfields, particularly in low-permeability reservoirs, heavy crude oil reservoirs, and thin reservoirs. This technique can enhance oil recovery and reduce costs. The operation procedures are as follows: firstly, milling the casing window in the pre-drilling formation and then reaming; and run in whipstock, then coiled tubing with nozzles at the outlet end perforating and entering into formation (as shown in Fig. 6). This technique was applied in nearly 10 wells in China. At present, the horizontal length using this technique extended to about $20 \mathrm{~m}$, and the borehole could be drilled in different formations or in different perforation orientation. However, the preparation and the operation procedure of the technique are comparatively complex. String must be run many times for milling and reaming, thus the drilling period will be prolonged.

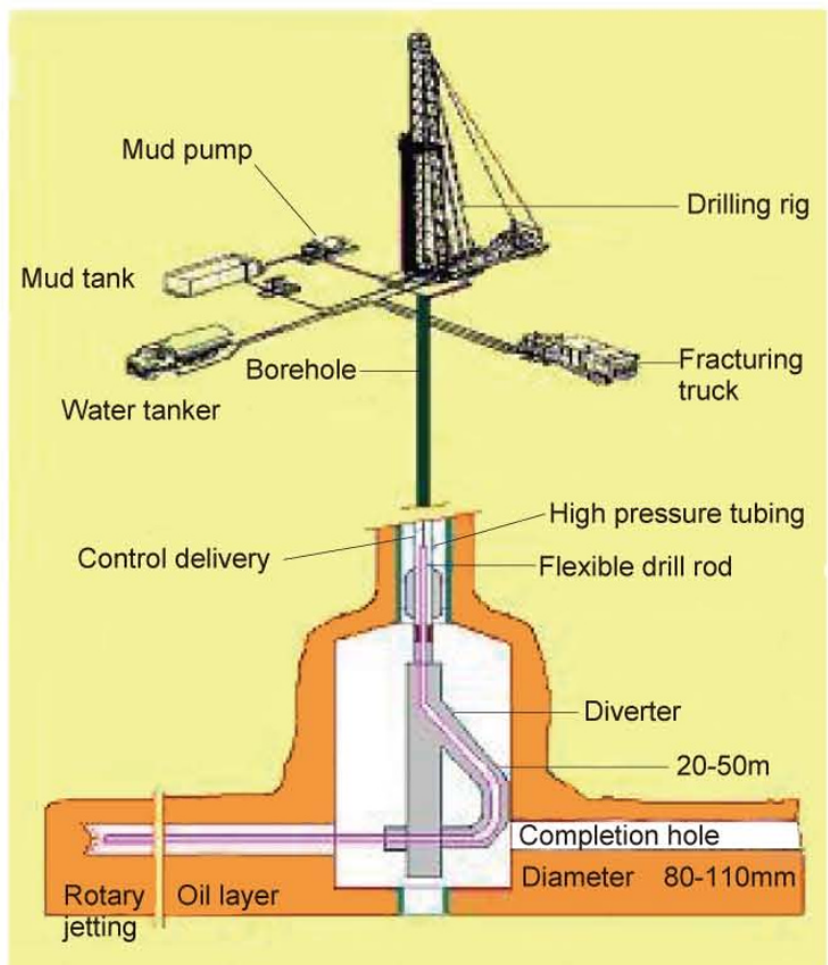

Fig. 6 Hydraulic deep-penetrating radial well

In recent years, new ultrashort-radius hydrajet drilling has been studied around the world (Bruni et al, 2007; Cirigliano and Talavera Blacutt, 2007; Su et al, 2008) (as shown in Fig. 7). Procedures are as follows: 1) Run in a diverter which was fixed with a tubing anchor and a directional sub using electric logging to confirm the azimuth of the diverter. 2) Run in the coiled tubing using abrasive water jet with the working medium containing quartz sand then perforate the casing directly. Afterwards pull out the coiled tubing, then replace the nozzles by using clean water jet nozzles, and coiled tubing is run in the hole again through the diverter and entered the formation while clean water is injected from the window. After drilling one branch borehole with coiled tubing the operator can drill repeatedly by removing or turning the diverter. 


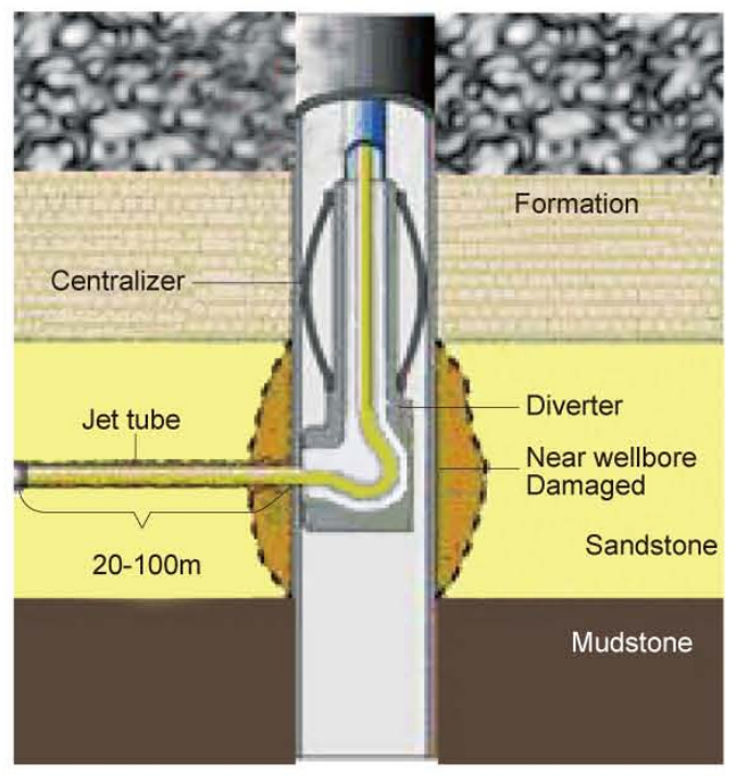

Fig. 7 Radial drilling with hydrajet

In 2007 , the technique used a $3 / 4$ inch junk bit to mill casing, then the bit was pulled out and $1 / 2$ inch coiled tubing was run to jet the formation. At each level, four lateral boreholes were drilled at $90^{\circ}$ and the maximum length extended to $100 \mathrm{~m}$ with a diameter of $50 \mathrm{~mm}$. This technique was applied in 22 wells in Argentina and achieved significant stimulation effects (Bruni et al, 2007). At present, the maximum depth using this technique extends to 3,800 $\mathrm{m}$ (Cirigliano and Talavera Blacutt, 2007). The water jet laboratory of the China University of Petroleum has already designed a surface model machine and has done some experiments, and field tests will later be conducted ( $\mathrm{Su}$ et al, 2008).

\section{Removal of sand particles and plugs with rotating pulsed cavitating jet in horizontal wells}

With an increase in the use of horizontal wells, it becomes more and more important to remove effectively the sand particles and plugs in the screens in horizontal wellbores. The removal of sand particles and plugs in horizontal wellbores with rotating self-resonating cavitating water jets was performed in oilfields, which showed promising and cost effective prospects (as shown in Fig. 8). In field operation, the tool is put down to the intervals of interest with tubing and moved up and down by the workover rig. The rotating pulsed cavitating jet flow, compared with the conventional axial stable flow, can avoid the sand particles depositing in the horizontal annulus and washing the screen, with concentrated hydro-power, along the inside circumference to remove the plug. This technique was successfully and effectively applied in thousands of vertical production and injection wells ( $\mathrm{Li}$ et al, 2002). Four successful field cases in the Changqing Oilfield in China show that this technique has great advantages and potential applications in removing sand particles and plugs in sand control screens in the horizontal wells ( as shown in Table 1).
Table 1 Production of four wells after jet operation

\begin{tabular}{cccc}
\hline Well & $\begin{array}{c}\text { Dynamic oil level } \\
\mathrm{m}\end{array}$ & $\begin{array}{c}\text { Oil production } \\
\mathrm{m}^{3} / \mathrm{d}\end{array}$ & $\begin{array}{c}\text { Water production } \\
\mathrm{m}^{3} / \mathrm{d}\end{array}$ \\
\hline Yuandongping 5 & 850 & 52.9 & 0 \\
Yuandongping 6 & 1150 & 36.6 & 0 \\
Yuandongping 2 & 2.1 & 5.1 & 0 \\
Yuandongzhong 2 & 1200 & Oil droplets & 36.6 \\
\hline
\end{tabular}

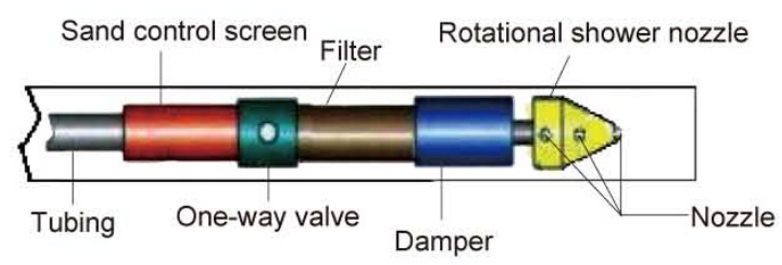

Fig. 8 The removal of sand particles and plugs with a rotating pulsed cavitating jet in horizontal wells

\section{Conclusions and prospects}

1) Jet parameters can be optimized experimentally, and experimental results provide fundamental information for well completion and fracturing. The field test results demonstrate that abrasive jet perforating can create clean oil and gas channels and increase productivity compared with conventional shaped charge jet perforating.

2) Deep-penetrating hydrajet perforating can use a nozzle and coiled tubing to jet into the formation, which can achieve greater penetration depth than abrasive perforating, and this technique provides a promising new method for increasing and stimulating low-permeability reservoirs and old wells.

3) High-pressure water jet fracturing can achieve multilayer or staged fracturing without mechanical sealing. This technique is a new approach to oil and gas stimulation and has been successfully applied in oil fields.

4) The new ultrashort-radius radial well technique with hydrajet can drill horizontal holes to about $100 \mathrm{~m}$. It also can shorten the sidetrack drilling period of old wells, reduce costs and greatly increase well productivity.

5) Field tests show that the removal of sand particles and plugs with a rotating pulsed jet in horizontal wells has many advantages.

\section{Acknowledgements}

The authors express their appreciation to the National Natural Science Foundation of China (No.50774089) and the High-tech Research and Development Program of China (No.2007AA09Z315) for the financial support of this work.

\section{References}

Bruni M, Biassotti H and Salomone G. Radial drilling in Argentina. Paper SPE 107382 presented at 2007 SPE Latin American and Caribbean Petroleum Engineering Conference, Buenos Aires, 15-18 
April. 2007

Cirigliano R A and Talavera Blacutt J F. First experience in the application of radial perforation technique in deep wells. Paper SPE 107182 presented at 2007 SPE Latin American and Caribbean Petroleum Engineering Conference, Buenos Aires, 15-18 April. 2007

Cobbett S. Sand jet perforating revisited. SPE Drilling \& Completion. 1999. 14(1): 28-33

Dickinson W, Auderson R R and Dickinson R W. The ultrashort-radius radial system. SPE Drilling Engineering. 1989. Sept.: 247-254

He H Q and Hu Q F. The technique of water jet deep-penetration reforming the near well-bore area. Proceedings of 8th Pacific Rim International Conference on Water Jet Technique held in Qingdao, China, 10-12 October, 2006. 230-237

Kobayashi R. Occasional thoughts on research basics and application. Jet Engineering. 2007. 24(3): 1-5 (in Japanese)

Li G S, Huang Z W, Niu J L, et al. Productivity-enhancing technique of deep penetrating perforating with high pressure water jet. Petroleum Science and Technology. 2007. 25(3): 289-297

Li G S, Huang Z W, Zhang D B, et al. Study of treatment of near wellbore formation processed with high pressure rotating water jets. Petroleum Science and Technology. 2002. 20(9\&10): 961-972

Li G S, Niu J L, Song J, et al. Abrasive water jet perforation: an alternative approach to enhance oil production. Petroleum Science and Technology. 2004. 22(5\&6): 491-504

Li G S, Shen Z H, Zhou C S, et al. Investigation and application of selfresonating cavitating water jet in petroleum engineering. Petroleum Science and Technology. 2005. 23(1): 1-15
Maurer W C. Advanced drilling techniques. Tulsa: Petroleum Publishing Company. 1980. 1-30

Peters A D and Henson S W. New well completion and stimulation techniques using liquid jet cutting technique. Paper SPE 26583 presented at the 68th SPE Annual Technical Conference and Exhibition, Houston, 3-6 October 1993

Shen Z H. Water Jet Technique in Petroleum Engineering. Dongying: University of Petroleum Press. 1997. 390-440 (in Chinese)

Summers D A. Water Jetting Technology. E \& FN Spon, An Imprint of Chapman \& Hall. 1994. 1-20

Surjaatmadja J B, Grundmann S R, McDaniel B, et al. Hydrajet fracturing: an effective method for placing many fractures in openhole horizontal wells. Paper SPE 48856 presented at 1998 SPE International Conference and Exhibition, Beijing, 2-6 November 1998

Surjaatmadja J B, Willett R, McDaniel B W, et al. Selective placement of fractures in horizontal wells in offshore Brazil demonstrates effectiveness of hydrajet stimulation process. Paper SPE 90056 presented at SPE Annual Technical Conference and Exhibition, Houston, Texas, 26-29 September 2004,

Su X L, Li G S, Huang Z W, et al. Continuous coiled tubing drilling technique research and application development. Natural Gas Industry. 2008. 28(8): 55-57, 66 (in Chinese)

Vijay M M. Advances in the applications of high speed fluid jets. Proceeding of the 4th Pacific Rim International Conference on Water Jet Technique, Shimizu, Japan, 1995. 27-46

(Edited by Sun Yanhua) 